A BETTING MARKET:

DESCRIPTION AND THEORETICAL EXPLANATION OF BETS IN PELOTA MATCHES

Loreto Llorente

Josemari Aizpurua

D.T.2006/03 


\title{
A BETTING MARKET: \\ Description and a theoretical explanation of bets in Pelota Matches.
}

\author{
Loreto Llorente \\ Josemari Aizpurua
}

\begin{abstract}
In Pelota matches, bets are made between viewers through a middleman who receives $16 \%$ of the finally paid amount. In this paper a description of the way bets are made and an explanation of the existence of those markets is presented. Taking betting markets as a simplified analogy for financial markets we have searched for the explanation in a world where both sides of the market are not different in believes and preferences. Taking observations from actually made bets a preliminary analysis about the biases of those markets is presented.
\end{abstract}




\section{A DESCRIPTION OF THE PELOTA BETTING SYSTEM}

All Pelota ("Pelota Vasca") matches are played by two teams: reds $(R)$ and blues $(B)$ play against each other by hitting alternatively a ball against a wall in a court called frontón. The starter hitting team is chosen throwing a coin. When a team makes an error the opponent scores one point and starts again a new point hitting the ball. The team that accumulates a fixed number of points wins the match.

On these matches a bet is described by two quantities that inform on the odds: a quantity of money the bettor losses when failing his prediction about which the winner team is and an amount of money the bettor wins if he guesses right. Bets can be made during the whole match, so while points are scored, odds change. A bettor can arrange as many bets as he wants to, provided another person that accepts the bets is founded. It is possible then to edge a bet made at the beginning of the match in favour of a team, betting latter on the opposite team allowing to study how new information affects the decisions of betting.

This type of betting system is popular in Pais Vasco (Basque Country), Navarra (Navarre), and La Rioja, where several Pelota games are being played. There are slight differences between the different types of games. In what follows we will study the betting system in a particular game called remonte. ${ }^{1}$ In America a different kind of game Jai-Alai or Cesta-Punta can also be seen. Betts are also made in Jai-Alai but the betting system in America is totally different to the system described here.

\subsection{A brief description of the betting market in REMONTE}

The Remonte game is a modality of Pelota. This game is played in a frontón, which consists of the playing court limited by tree walls, the front one, the left one and the back one. The frontón size is about 54 meters long, 12 meters wide and 11 meters high.

In this game reds and blues hit a ball with an artefact tied to the players' hand called the cesta. The teams are generally composed of two players each but occasionally could be composed of one or three players as well. The team who first accumulates 40 points wins the match. One match usually lasts around an hour.

Throughout a whole Remonte match a screen (table 1) shows the effective odds in the market and the score at the moment.

Table1 "the screen":

(reds) (blues)

\begin{tabular}{|c|c|}
\multicolumn{1}{c}{ odds } & \multicolumn{1}{c}{ score } \\
\hline$O_{R}$ & $\mathrm{~s}_{\mathrm{r}}$ \\
\hline$O_{B}$ & $\mathrm{~s}_{\mathrm{b}}$ \\
\hline
\end{tabular}

$O_{R}$ is the amount of money a bettor risks betting on reds. $O_{B}$ is the amount of money a bettor risks betting on blues. $\mathrm{s}_{\mathrm{r}}\left(\mathrm{s}_{\mathrm{b}}\right)$ is the red (blue) team's score.

\footnotetext{
${ }^{1}$ Notice that the rules of the betting system are not written, thus all our explanations are based on information obtained in the frontón. More specifically, our study is based in the information collected by Loreto Llorente at the Euskal Jai Berri, a frontón where the Pelota's game played is remonte. This frontón was chosen because it has an installation of screens where one can see the odds at which you can bet in any moment of the game, a very helpful peculiarity to obtain field data.
} 
Picture: The reds and the blues playing a Pelota game in the fronton.

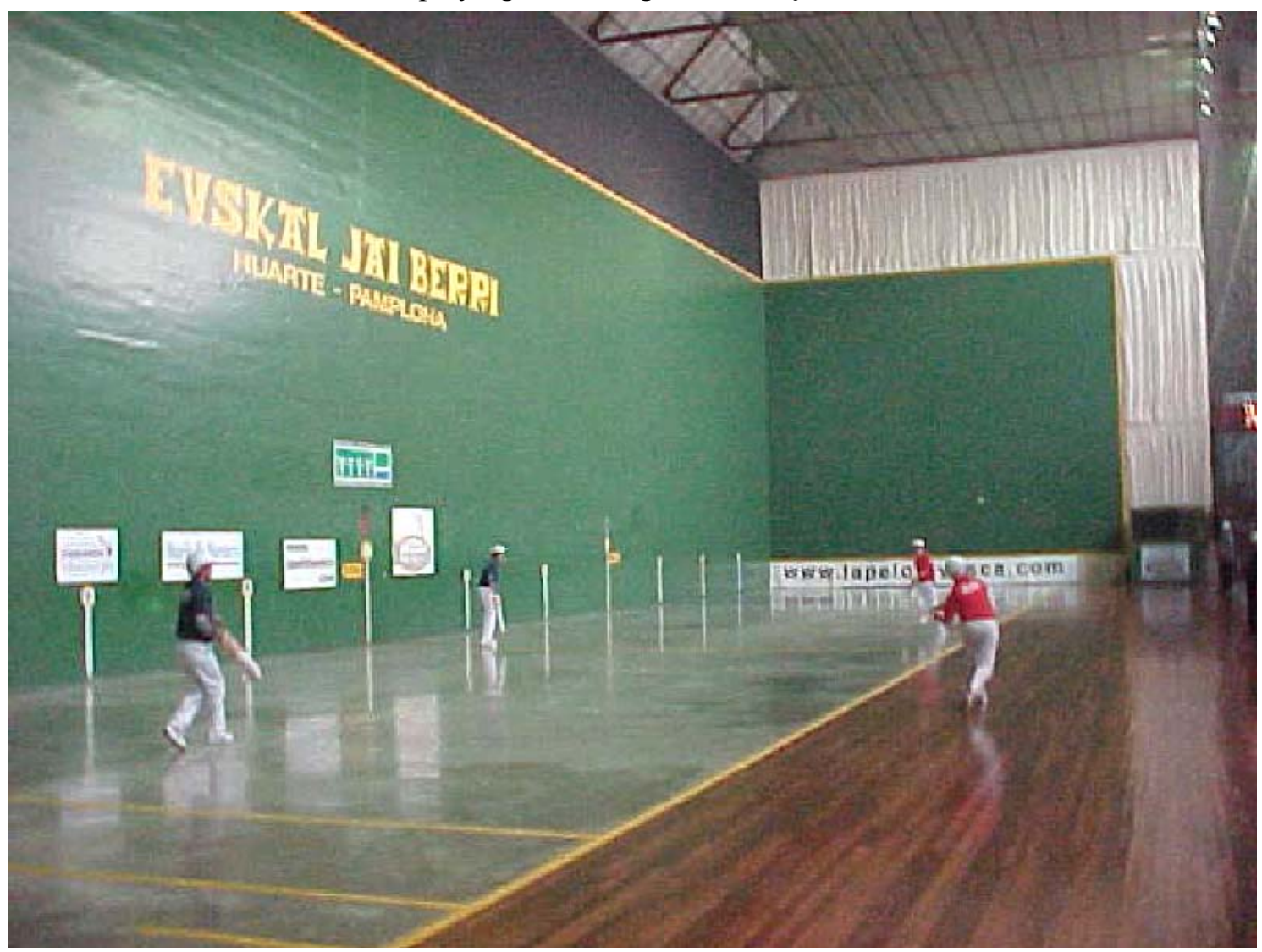

The odds consist of two numbers, the bigger one is always 100 euros and the smaller one varies as points are played between 2 and $100 .^{2}$

Example:

(reds)

(blues)

\begin{tabular}{|c|c|}
\multicolumn{1}{c|}{ odds } & score \\
\hline 100 & 5 \\
\hline 80 & 2 \\
\hline
\end{tabular}

In this moment red team scores 5 and blue team scores 2 . The odds are 100 to 80 , denoted $(100,80)$. The bettor who bets on reds risks 100 euro to win 80 and the one who bets on blues risks 80 euro to win $100 .{ }^{3}$ Bets are always between viewers so if a viewer gets one bet on red there must be another viewer who bets on blue. What will happen when the game is over?

\footnotetext{
${ }^{2}$ Generally the smaller odd is one number of the set $\{2,3,4,5,6,8,10,12,15,20,25,30,40,50,60,70$, $80,90,100\}$, numbers like 55 are also possible but unusual.

${ }^{3}$ In what follows we will follow this convention to describe the different bets.
} 
bet on reds $A$ bettor on reds will loose 100 euros if blues win the match. Otherwise, if reds win the match the bettor will win 80 euros minus 16 percent of the commission, that is to say he will have 67.2 euros. .

bet on blues A bettor on blues will loose 80 euros if reds win the match. Otherwise, if blue wins the match the bettor will win 100 euros minus 16 per cent, the total amount of 84 euros.

This describes a single bet. A bettor can make as many bets as he wants to, provided, as has been told, that there is another bettor on the other side.

\subsection{How are bets made?}

There are several middlemen between the players and the audience looking at the latter. A bettor's demand is pointed out to the middleman by a convention: touching the face indicates a demand to bet on red and touching the arm a bet on blue. The bettor also indicates to the middleman how many bets he wants to. When the middleman sees a signal, he shouts the odds looking for some one who wants to accept the bet. The shouted odds are the ones everybody sees on the screen. When he finds another person that matches a demanded bet, provided the demander accepts, the middleman prints two receipts, a red and a blue one where the date, the name of the players on the match, the odds and the number of bets are recorded. He introduces each receipt in a tennis ball and throws the red one at the person that bets on red and the blue one at the person that bets on blue. The middleman keeps shouting the odds until all demanded bets have found its corresponding opponent-bettor on the other side. At the end of the match people goes to pay to or to be paid by the middleman. The loser will have to pay the amount on the screen, but the winner is paid the money on the screen minus the percentage the enterprise takes (16 per cent). This commission is divided equally in two parts, the 8 per cent is taken by the enterprise that pays the players, and the other half is for the middlemen who make the bets possible, and who must pay the winner even in the unusual but possible case that the loser has not paid. Because this possibility is real if somebody wants to bet big quantities of money, the middleman is not going to take him into account unless he trusts him.

\subsection{How are the odds chosen?}

In remonte there is an auctionaire who introduces the odds that appear at the screen. We call the coordinator. He is a man who has been a player and a middleman for many years. This man is an expert on remonte, possibly the man who knows best the game in the frontón. He chooses the balls player play the match with ${ }^{4}$, and he introduces the odds at which people bet. He sits in front of a computer, in a privileged place behind the audience, where he can follow the match and see the audience and all the middlemen. He introduces the odds that appear in the screens. There are some general rules that the coordinator follows to fix and change the odds:

\footnotetext{
${ }^{4}$ The ball is very important in the game. Balls, always hand made, can be faster or slower and different types of balls suit better to some players .
} 
If there is no reason to think of a team as the favourite just before the match starts, the screen is

(reds)

(blues)

\begin{tabular}{|c|c|}
\hline \multicolumn{1}{c|}{ odds } & \multicolumn{1}{c}{ score } \\
\hline 100 & 0 \\
\hline 100 & 0 \\
\hline
\end{tabular}

If there is a favourite team, the odds may be different. For example, if red is favourite, with the same score we could have odds $\left(O_{R}, O_{B}\right)$ equal to $(100,80)$.

Once it's clear which the initial odds are, as the match goes on and points are made, the general rule is that the difference between the amounts of the odds increases 10 euros on the team who has scored the point, keeping in mind that the bigger amount of the two odds is always 100 .

If the odds differ by more than $70(100,30)$, the odds change only 5 euros for each point. If the odds differ by more than 90 , the odds change only 2 euros for each point. When one team has accumulated approximately 30 points, as points are scored, the odds change double for each point, and triple or quadruple when the end is close enough. For example if the score is equal to $(38,39)$, the odds would be $(40,100)$.

Of course, sometimes these rules are modified because of the change in the supply and demand of the audience. When a middleman finds two persons who want to bet at some different odds from that of the screen, the middleman has to ask the coordinator to change the odds in the screen, so that he can print the receipts for the bettors. There are no bets in the frontón at odds different from that at the screens. In general the odds vary mainly as the above rules indicate. It's important to realize that the coordinator is working for the firm that organizes Pelota matches and so his goal could be described as making people bet as much as possible. So we can confidently assume that the odds he introduces are the odds at which people are willing to bet the most.

\subsection{A monetary peculiarity}

Before 2002, the peseta was the currency in Spain ( 1 euro $=166,386$ pesetas $)$ but in the frontón all counts were made in duros, $(1$ duro $=5$ pesetas $)$. Before the entry of the euro the odds where the same but multiplied by 10 , i.e., the odds then where 1.000 to 1.000 when there was no favourite team. It is worthwhile to notice that the adoption of the euro as the currency made the minimum stake on the favourite be multiplied by 3.33 times, from 1.000 duros to 100 euros (from 5.000 to $16.638,6$ pesetas). Although we don't do it here and as it is noticed in Köbberling, V., Schwieren, C., and Wakker, P. P. (2004), it would be interesting to study how the euro affected the betting decisions due to the nominal change in the minimum stake. 


\title{
2. A THEORETICAL MODEL WITH IDENTICAL INDIVIDUALS: Rank dependent expected utility (RDEU)
}

\author{
An economist is someone who, seeing that something works in \\ practice, asks if it can also work in theory. \\ ANONYMOUS \\ Taken from A.Blinder, E.Canetti,D.Lebow, and J.Rudd, \\ Asking About Prices. A New Approach to Understanding \\ Price Stickiness.
}

It is recognised that although expected utility maximization is the benchmark for normative approaches it is not a powerful tool when an observed behaviour needs to be explained. In betting markets it is observed that bets are not an insignificant fraction of bettors income bettors are wage-earning workers or owners of small firms - and certainly bets are not bettor's whole wealth. Within the expected utility paradigm it is not possible to explain a bet between equal risk-averse EU maximizers. If risk-taking behaviour is assumed, and bets do exist, the optimal behaviour for an individual is to bet all his wealth, which, as has been said, is not supported by evidence. We wonder if there were a model that explained the existence of bets and where bettors' optimum is to bet only part of his wealth. We have found such a model, it is the rank-dependent expected utility model (RDEU) introduced by Quiggin in $1979^{5}$, see Quiggin, J. (1982).

\subsection{The theoretical model: notation}

We analyze pelota bets under Quiggin's RDEU model.

The theoretical framework of theory of choice under uncertainty is the one followed in Quiggin, J. (1993). We deal with individual preferences over a set $\chi$ of outcomes and an associated set, $y$, of random variables, or prospects, taking values in $x$. Elements of $x$ are denoted $x$, and elements of $y$ are denoted $y$. In what follows, $\chi$ is assumed to be an interval in $\mathfrak{R}_{+}$interpreted in terms of income or wealth levels. The outcome space is totally ordered by a preference relation, denoted by $\gtrsim$. The associated indifference relation is denoted by $\sim$. Prospects will be represented in the form

$$
\{\mathbb{x}, \mathfrak{p}\}=\left\{\left(x_{1}, x_{2}, \ldots x_{n}\right) ;\left(p_{1}, p_{2}, \ldots, p_{n}\right)\right\}
$$

\footnotetext{
${ }^{5}$ RDEU model was first developed in Quiggin's 1979 undergraduate thesis and published by him in the 1982 Journal of Economic Behavior and Organization. Unfortunately, this paper did not receive the attention it deserved, and the rank-dependent model was independently discovered and published at least three more times: in a special case by Yaari in 1987, by Allais in 1988, and in a context of social welfare measurement by Weymark in 1981.
} 
where $p_{i}$ is the probability of outcome $x_{i}, \sum_{i=1}^{n} p_{i}=1$, and the $x_{i}$ are weakly ordered from worst to best, so that $x_{1} \lessgtr \ldots \lesssim x_{n}$.

Before continuing with the model let us recall the main difference between RDEU model and the EU model. In the RDEU functional the outcome's utilities are multiplied not by the probability but by a weighted probability. Each probability is "modified" by a probability weighting function but the weight attached to a given probability depends not only on the probability itself but also on the rank of the outcome associated with that probability. This is done by applying a probability weighting function not directly on the probability but on the cumulative probability of the outcomes worse that the one being weighted. So it is important to notice that before obtaining the RDEU of a prospect, this prospect must be presented in a particular way that is with outcomes ordered from worst to best.

Formally, the cumulative probability of $x$, denoted $F(x)$, is given by $P_{r}\{y<x\}=\sum_{x_{i} \leq x} p_{i}$. RDEU is based on a probability weighting function $q:[0 ; 1] \rightarrow[0 ; 1]$ applied, not to the probabilities of individual events, but to the cumulative distribution function. The RDEU functional is given by

$$
V(\{x ; p\})=\sum_{i=1}^{n} U\left(x_{i}\right) h_{i}(p)
$$

where

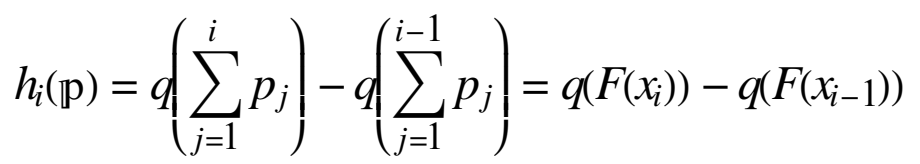

In our specific market, similarly to the betting market in Pelota, we consider two states of the world "the winners are the reds", $r$, and "the winners are the blues", $b$. Bettor $i \in\{1, \ldots, \mathrm{N}\}$ has an endowment of $W_{i} \in \mathfrak{R}_{+}$. Call $p_{r}\left(p_{b}\right)$ the objective probability for event $r(b)$; as ties are not allowed $p_{b}=1-p_{r}$. The odds will be represented by $\left(O_{R}, O_{B}\right)$, where $O_{R}\left(O_{B}\right)$ is the money you risk if you stake one unit on event $r(b)$, the money you loss when event $r(b)$ does not occur. It may be helpful to think on those odds as a price relation at which one can trade "money if state of the world $b$ occurs" for "money if the state of the world $r$ occurs". We consider middlemen's commission, $t \in[0,1)$, as the percentage of the money won in a bet that has to be paid to the middleman as a commission.

Therefore to stake one single bet on $r$ means to select the prospect

$$
\left\{\left(W_{i}-O_{R}, W_{i}+O_{B}(1-t)\right) ;\left(1-p_{r}, p_{r}\right)\right\} .
$$

And to stake one single bet on $b$ means to select the prospect

$$
\left\{\left(W_{i}-O_{B}, W_{i}+O_{R}(1-t)\right) ;\left(p_{r}, 1-p_{r}\right)\right\} .
$$


As more than one bet can be staked in each of both colors we consider two special subsets of prospects among which bettor $i$ can choose, $\mathcal{R}, \mathcal{B} \subseteq \mathcal{Y}$. We denote $S R_{i} \in \mathcal{R}$ the prospect selected by bettor $i$ when he stakes $S R$ bets on the reds, which is the prospect

$$
\left\{\left(W_{i}-O_{R} S R_{i}, W_{i}+O_{B}(1-t) S R_{i}\right) ;\left(1-p_{r}, p_{r}\right)\right\} \text { and }
$$

$S B_{i} \in \mathcal{B}$ the prospect selected when staking $S B$ bets on the blues, which is the prospect

$$
\left\{\left(W_{i}-O_{B} S B_{i}, W_{i}+O_{R}(1-t) S B_{i}\right) ;\left(p_{r}, 1-p_{r}\right)\right\} .
$$

These prospects can be represented in a graph with horizontal axis showing consumption in case $r$ occurs and the vertical axis representing consumption in case b occurs. It follows such a graph.

$$
\begin{array}{ll}
\text { - - Betting on blue } & S_{r}=\text { number of bets on } r \quad S_{0}=\text { there are no bets } \\
\text { Betting on red } & S_{b}=\text { number of bets on } b
\end{array}
$$

1.A. Consumption set with $t=0$

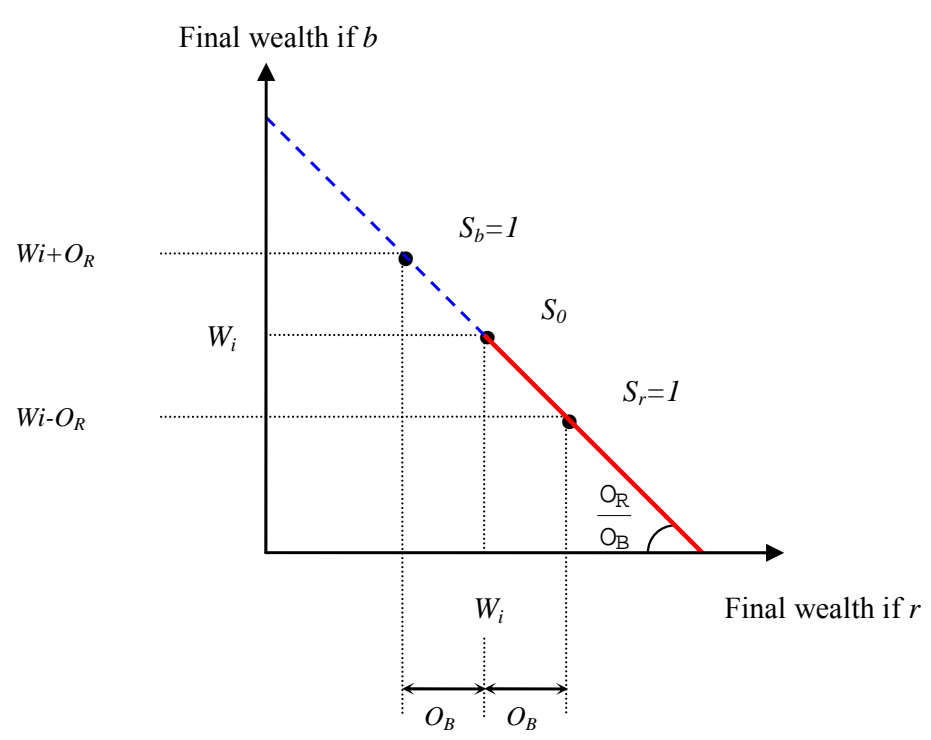




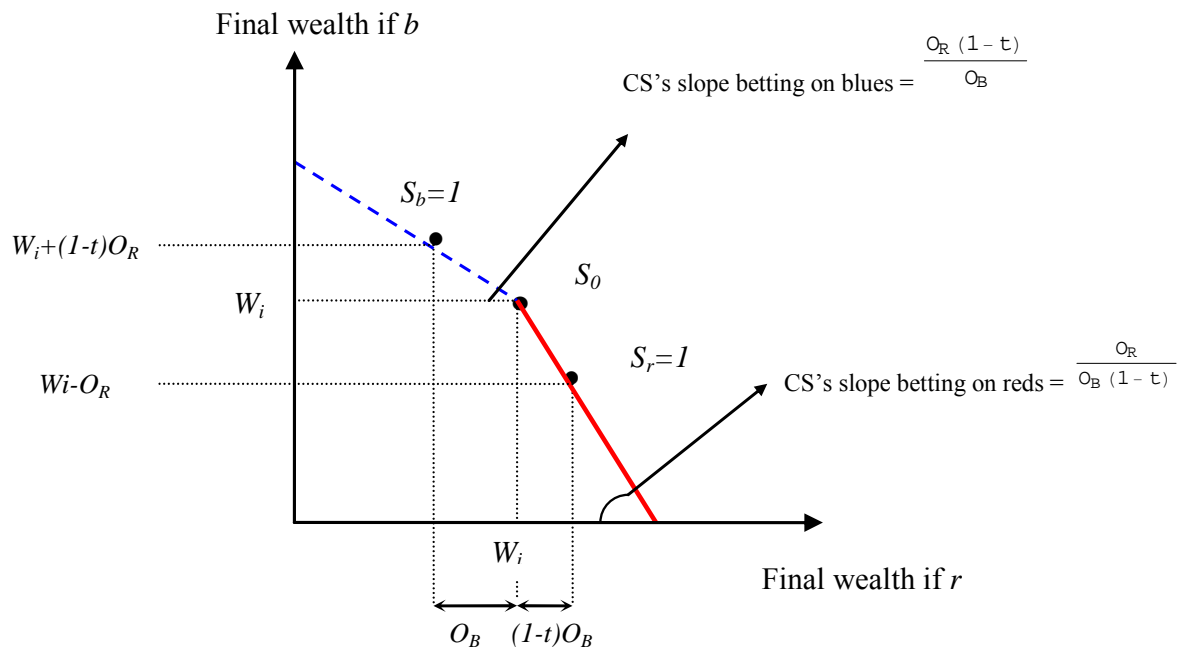

Then a bettor's utilities for each of the possible prospects are

$$
\begin{gathered}
V\left(S R_{i}\right)=q\left(1-p_{r}\right) U\left(W_{i}-O_{R} S R_{i}\right)+\left(1-q\left(1-p_{r}\right)\right) U\left(W_{i}+O_{B}(1-t) S R_{i}\right), \text { and } \\
V\left(S B_{i}\right)=q\left(p_{r}\right) U\left(W_{i}-O_{B} S B_{i}\right)+\left(1-q\left(p_{r}\right)\right) U\left(W_{i}+O_{R}(1-t) S B_{i}\right)
\end{gathered}
$$

From this expressions we obtain the graphical representation of indifference curves (IC) in “Appendix: RDEU Maximizers' Indifference Curves" in page 21.

Bettor i's optimal decision is given by

$$
S^{* *}\left(p_{r}, O_{R}, O_{B}, W_{i}\right)=\mid \begin{array}{ll}
S R_{i}^{*} & \text { if } V\left(S R_{i}^{*}\right) \geq V\left(S B_{i}^{*}\right) \\
S B_{i}^{*} & \text { if } V\left(S R_{i}^{*}\right) \leq V\left(S B_{i}^{*}\right)
\end{array},
$$

where $S R_{i}^{*}$ is obtained solving the problem

$$
\max _{S R_{i} \in\left[0, \frac{W_{i}}{O_{R}}\right]} V\left(S R_{i}\right)
$$

and $S B_{i}{ }^{*}$ is such that

$$
\max _{S B_{i} \in\left[0, \frac{W_{i}}{O_{B}}\right]} V\left(S B_{i}\right)
$$

Thus bettor $i$ decides either to stake on $r, S R_{i} \in\left[0, \frac{W_{i}}{O_{R}}\right]$, or to stake on $b, S B_{i} \in\left[0, \frac{W_{i}}{O_{B}}\right]$, it is not possible to bet a negative amount or to bet a bigger amount you can afford with your endowment. 
The first order conditions for an interior solution are $S R_{i}^{*}\left(p_{r}, O_{R}, O_{B}, W_{i}\right)$ such that

$$
\begin{aligned}
& \frac{1-q\left(1-p_{r}\right)}{q\left(1-p_{r}\right)} \frac{U^{\prime}\left(W_{i}+O_{B} S R_{i}(1-t)\right)}{U^{\prime}\left(W_{i}-O_{R} S R_{i}\right)}=\frac{O_{R}}{O_{B}(1-t)} \\
& \text { IC's slope }{ }^{6} \quad \text { CS's slope }
\end{aligned}
$$

and $S B_{i}^{*}\left(p_{r}, O_{R}, O_{B}, W_{i}\right)$ such that

$$
\frac{q\left(p_{r}\right)}{1-q\left(p_{r}\right)} \frac{U^{\prime}\left(W_{i}-O_{B} S B_{i}\right)}{U^{\prime}\left(W_{i}+O_{R} S B_{i}(1-t)\right)}=\frac{O_{R}(1-t)}{O_{B}} .
$$

Second order condition tell us that $\mathrm{U}^{\prime \prime}(\mathrm{x})<0$ is a sufficient condition for the maximization. ${ }^{7}$

Proposition 1 Let a Pelota betting market be composed of identical RDEU maximizers with a concave utility function. Then a necessary condition for a bet to take place is that bettors are optimistic as defined in Quiggin, J. (1982).

Proof:

A necessary condition for the existence of a bet is one bettor betting on reds and another on blues but as bettors are equal we need to obtain $S R_{i}^{*}$ and $S B_{i}^{*}$ greater than 0 "for the same bettor".

As $t$ is on $[0,1)$, we know that

$$
\begin{aligned}
& \frac{O_{R}}{O_{B}(1-t)} \geq \frac{O_{R}(1-t)}{O_{B}} \quad \text { which together with (1) and (2) implies that } \\
& \frac{1-q\left(1-p_{r}\right)}{q\left(1-p_{r}\right)} \frac{U^{\prime}\left(W_{i}+O_{B} S R_{i}(1-t)\right)}{U^{\prime}\left(W_{i}-O_{R} S R_{i}\right)} \geq \frac{q\left(p_{r}\right)}{1-q\left(p_{r}\right)} \frac{U^{\prime}\left(W_{i}-O_{B} S B_{i}\right)}{U^{\prime}\left(W_{i}+O_{R} S B_{i}(1-t)\right)},
\end{aligned}
$$

that is to say that IC's slope when betting on reds must be greater or equal to de IC's slope when betting on blues. In addition, as bettors' utility function is concave, $\mathrm{U}^{\prime}(\mathrm{X})<0$, it follows that

$$
\frac{U^{\prime}\left(W_{i}+O_{B} S R_{i}(1-t)\right)}{U^{\prime}\left(W_{i}-O_{R} S R_{i}\right)}<\frac{U^{\prime}\left(W_{i}-O_{B} S B_{i}\right)}{U^{\prime}\left(W_{i}+O_{R} S B_{i}(1-t)\right)} \text { thus, in order to (3) be true, }
$$

\footnotetext{
${ }^{6}$ See the section “Appendix: RDEU Maximizers' Indifference Curves" in page 21 in order to see the IC's shape under this model.

${ }^{7}$ Second order condition for the optimization establishes that the following is true,$$
\begin{aligned}
& \frac{\delta^{2} V\left(\mathrm{SR}_{i}\right)}{\delta \mathrm{SR}_{i}^{2}}=q\left(1-p_{r}\right) U^{\prime \prime}\left(W_{i}-O_{R} \mathrm{SR}_{i}\right)\left(-O_{R}\right)^{2}+\left(1-q\left(1-p_{r}\right)\right) U^{\prime \prime}\left(W_{i}+O_{B}(1-t) \mathrm{SR}_{i}\right)\left(O_{B}(1-t)\right)^{2} \leq 0 \text { and } \\
& \frac{\delta^{2} V\left(\mathrm{SB}_{i}\right)}{\delta \mathbf{S B}_{i}^{2}}=q\left(p_{r}\right) U^{\prime \prime}\left(W_{i}-O_{B} \mathrm{SB}_{i}\right)\left(-O_{B}\right)^{2}+\left(1-q\left(p_{r}\right)\right) U^{\prime \prime}\left(W_{i}+O_{R}(1-t) \mathrm{SB}_{i}\right)\left(O_{R}(1-t)^{2} \leq 0\right.
\end{aligned}
$$ 


$$
\begin{aligned}
& \frac{1-q\left(1-p_{r}\right)}{q\left(1-p_{r}\right)}>\frac{q\left(p_{r}\right)}{1-q\left(p_{r}\right)} \text {, operating } 1-q\left(1-p_{r}\right)>q\left(p_{r}\right) \text { which is Quiggin's definition of } \\
& \text { optimistic. }
\end{aligned}
$$

The presence of those optimistic RDEU maximizers, provide us with a model where an interior solution makes possible the existence of bets even if commissions are charged. Graphically it is not difficult to see that this is possible in case of optimistic RDEU maximizers with concave utility function as in the graph bellow, the indifference curves shapes in this model are explained in detail in “Appendix: RDEU Maximizers' Indifference Curves” in page 21.

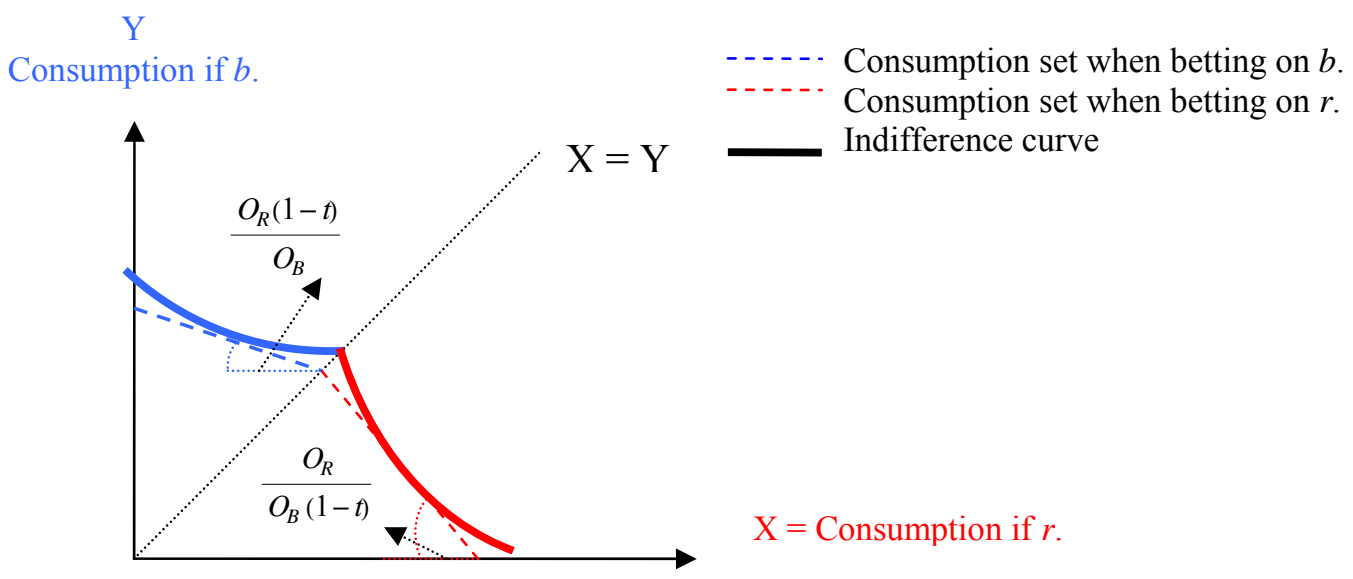

We can see in the graph that for the same bettor $S R_{i}{ }^{*}$ and $S B_{i}{ }^{*}$ are both greater than cero. So, in this case, there would be a bet in the Pelota market between two equal RDEU maximizers.

\subsection{Notes on the probability weighting function}

Since the Allais paradox ${ }^{8}$ was presented in the fifties, much research on observed violations of EU theory was developed. Edwards in the 1950's and Kahneman, D. and Tversky, A. (1979) in Prospect theory proposed to modify each probability by a nonlinear "decision weight". But applying the probability weighting function directly to the probability of each event has an important drawback, violations of stochastic dominance occurs. This trouble was solved by Quiggin's rank dependent model published in 1982. The clue is to apply the weighting function not directly to the outcome's probability but to the cumulated probability of outcomes less preferred than the one weighted. ${ }^{9}$ The weighting function is the basis of rank dependent expected utility and a very important characteristic in cumulative prospect theory. Thus we dedicate this section to it.

\footnotetext{
${ }^{8}$ Allais, M. (1953). Le comportement de l'homme rationnel devant le risqué, critique des postulats et axioms de l'école Américaine. Econometrica 21: 503-46.

${ }^{9}$ This way of transforming probabilities has been also introduced in prospect theory developing the cumulative prospect theory in Tversky, A. and D. Kahneman (1992).
} 
There is plenty of evidence that individuals overestimate low probabilities and underestimate high probabilities.

Remember the RDEU functional is given by

$$
V(\{x ; p)\}=\sum_{i=1}^{n} U\left(x_{i}\right) h_{i}(p),
$$

where

$$
h_{i}(\mathfrak{p})=q\left(\sum_{j=1}^{i} p_{j}\right)-q\left(\sum_{j=1}^{i-1} p_{j}\right)=q\left(F\left(x_{i}\right)\right)-q\left(F\left(x_{i-1}\right)\right)
$$

but studying bets on the frontón this takes a simple form. The prospects we evaluate have only two possible outcomes: one of them is a loss and the other is a gain. To evaluate the RDEU functional for any bet we have to order outcomes from worst to best and applying equations above we have

$$
V\left(\left\{\left(x_{1}, x_{2}\right) ;\left(p_{1}, p_{2}\right)\right\}\right)=U\left(x_{1}\right) q\left(x_{1}\right)+U\left(x_{2}\right)\left(1-q\left(x_{1}\right)\right) .
$$

Thus in this particular case, $q(p)$ is the weight attached to the probability of the worst outcome, when prediction fails. The weight attached to the best outcome is the complement to unit, (1 $\left.q\left(x_{1}\right)\right)$. Thus the basic weighting function, $q(p)$, is applied always to the worst outcome.

Let's call $p_{1}^{l-s}\left(p_{1}{ }^{f}\right)$ the probability of the worst outcome when betting on the long-shot (favourite). Remark that in case of betting on the long-shot, the basic weighting function is applied to a high probability of losing, $p_{1}^{l-s}>>0.5$, and when betting on the favourite, the weighting function $q(p)$ is applied to a small probability of losing, $p_{1}{ }^{f}<<0.5$.

We have already studied that a bet only can exist between equal bettors if individuals are optimistic which in our case means that

$$
q\left(p_{1}^{l-s}\right)+q\left(p_{1}^{f}\right)<1,
$$

that is to say, adding the weights that both bettors attach to the worst possible outcome adds less than the unit, and therefore the weights that both bettors attach to their best possible outcome adds more than the unit. Thus, regardless of the shape of the weighting function $q(p)$, for a bet to exist bettors have to be optimistic, that is to say $q(p)+q(1-p)<1$. So S-shaped that underestimate low probabilities, inversed S-shaped that over estimate low probabilities or convex that underestimate all the probabilities, are all allowed provided they satisfy the previously mentioned requirement.

A particular weighting function that fits our purposes and will be estimated later on is

$$
\pi(p)=\frac{\delta \mathrm{p}^{\gamma}}{\delta \mathrm{p}^{\gamma}+(1-p)^{\gamma}}
$$


This functional form is studied in Lattimore, P.K., J. K. Baker, and A. D. Witte. (1992). It has been estimated in empirical papers as in Gonzalez, R. and G. Wu (1999). For the median data they obtain for the weighting function $\delta=0.77$ and $\gamma=0.44 .^{10}$

When $\delta<1 \Longrightarrow \pi(\mathrm{p})+\pi(1-\mathrm{p})<1$. Then if we take $\mathrm{q}(p) \equiv \pi(p)$ this implies optimism. $\gamma$ measures the curvature; when $\gamma<1$ the function is first concave and after convex Thus we present an example with $\gamma=0.5$ and $\delta=0.5$

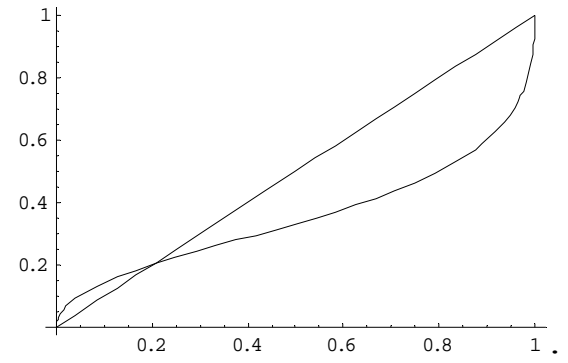

It is also an empirical finding that $\mathrm{P}^{*}$ (point where $q\left(p^{*}\right)=p^{*}$ ) is around 0.36 thus it follows an example with $\gamma=0.5$ and $\delta=0.77$

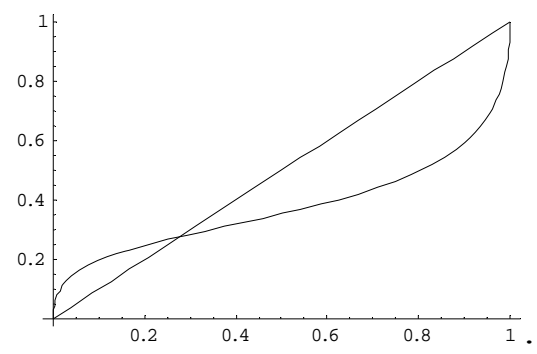

Therefore the equation

$$
q(p)=\frac{\delta p^{\gamma}}{\delta p^{\gamma}+(1-p)^{\gamma}}
$$

represents a set a weighting functions that allows for a shape that fits empirically observed behavior.

\footnotetext{
${ }^{10}$ This data is obtained for the power utility function on wealth, $v(x)=x^{\alpha}$, with $\alpha=0.49$.
} 


\section{EMPIRICAL STUDY: field data, a preliminary analysis}

Even though the Pelota betting system has operated for long, we have not found valid records about bets actually made. The firms that organize those markets do not publish data about the betting process. For that reason we collected the data that follow by ourselves while the bets were made. As has been told earlier, remonte bets were chosen precisely because their screen was very helpful for our purposes

We have collected data from 27 matches in the frontón. ${ }^{11}$ We are aware that those are not enough to obtain strong conclusions. Our purpose here is just to present a preliminary analysis about possible biases on those markets. We collected for each score, the odds and the approximate volume of bets. From this data base we obtain the table below where the odds appear in the first column. Here the odds are presented as pairs $\left(O_{f}, O_{l}\right)$ where $f$ denotes the favorite team and to which the higher number of the odds is associated, and $l$ corresponds to the non-favorite or long-shot team.

\begin{tabular}{|c|c|c|c|c|c|}
\hline \hline $\begin{array}{c}\text { Odds; } \\
\left(\boldsymbol{O}_{f}, \boldsymbol{O}_{\boldsymbol{I}}\right)\end{array}$ & Cases & $\begin{array}{c}\text { favorite } \\
\text { winnes }\end{array}$ & $\boldsymbol{\pi}_{f}^{l_{f}}$ & $\begin{array}{c}\text { favorite } \\
\text { losses }\end{array}$ & $\boldsymbol{\pi}_{\boldsymbol{l}}^{\boldsymbol{I}^{\prime}}$ \\
\hline$(1000,900)$ & 121 & $62(0,51)$ & 0,48 & $59(0,49)$ & 0,43 \\
\hline$(1000,800)$ & 68 & $29(0,43)$ & 0,51 & $39(0,57)$ & 0,4 \\
\hline$(1000,700)$ & 39 & $25(0,64)$ & 0,55 & $14(0,36)$ & 0,37 \\
\hline$(1000,600)$ & 51 & $38(0,75)$ & 0,58 & $13(0,25)$ & 0,34 \\
\hline$(1000,500)$ & 48 & $41(0,85)$ & 0,63 & $7(0,15)$ & 0,3 \\
\hline$(1000,400)$ & 33 & $21(0,64)$ & 0,68 & $12(0,36)$ & 0,25 \\
\hline$(1000,300)$ & 28 & $20(0,71)$ & 0,74 & $8(0,29)$ & 0,2 \\
\hline$(1000,250)$ & 12 & $8(0,67)$ & 0,77 & $4(0,33)$ & 0,17 \\
\hline$(1000,200)$ & 28 & $27(0,96)$ & 0,81 & $1(0,04)$ & 0,14 \\
\hline$(1000,150)$ & 16 & $16(1)$ & 0,85 & $0(0)$ & 0,11 \\
\hline$(1000,120)$ & 11 & $11(1)$ & 0,88 & $0(0)$ & 0,09 \\
\hline$(1000,100)$ & 20 & $20(1)$ & 0,89 & $0(0)$ & 0,08 \\
\hline$(1000,80)$ & 9 & $9(1)$ & 0,91 & $0(0)$ & 0,06 \\
\hline$(1000,60)$ & 3 & $3(1)$ & 0,93 & $0(0)$ & 0,05 \\
\hline$(1000,50)$ & 2 & $2(1)$ & 0,94 & $0(0)$ & 0,04 \\
\hline \hline
\end{tabular}

For each of the odds we have count the total number of times, when at those odds bets have been made. Our sample, then, has 489 cases when bets have been observed. In column 3, for each given odds, the number of times that the favourite team has turned out to be the winner is shown. Column 5 shows the number of times that the favourite has been defeated. Frequencies are in the same column in brackets.

\footnotetext{
${ }^{11}$ Data were collected in summer 2001, thus euro had not entry therefore the odds are multiplied by 10. The higher of the odds where 1000 duros instead of 100 euros.
} 
For each given odds betting on $l$ means accepting that $O_{l}$ will be lose with some probability denoted by $\pi_{f}^{l}$ and $O_{f}(1-t)$ will be gained with probability $1-\pi_{f}^{l}$. A bettor that bets on $l$ indicates that his subjective probability of the worse event (gains favourite) is $\pi_{f}^{l} \leq \frac{O_{f}(1-t)}{O_{f}(1-t)+O_{l}}$. This upper bound on the worse event for a bettor on $l$, with commission $t=0.16$, is shown in column 4 .

Similarly for a given odds betting on $f$ means accepting that $O_{f}$ will be lose with some probability denoted by $\pi_{l}^{f}$ and $O_{l}(1-t)$ will be gained with probability $1-\pi_{l}^{f}$. A bettor that bets on $f$ indicates that his subjective probability of the worse event (gains the non-favorite team) is $\pi_{l}^{f} \leq \frac{O_{l}(1-t)}{O_{l}(1-t)+O_{f}}$. This upper bound on the worse event for a bettor on $f$, with commission $t=0.16$, is shown in column 6 .

For any given odds the worse event for a bettor on $l$ is "favourite wins". The frequency of this event is shown in column 3 . And $\pi_{f}^{l}$ will be interpret as the weight a bettor on $l$ attaches to this frequency. Pairs (frecuency favourite wins, $\pi_{f}^{l}$ ) are represented by triangles on Figure 1.

Similarly, for any given odds the worse event for a bettor on $f$ is "favourite losses". The frequency of this event is shown in column 5 . And $\pi_{l}^{f}$ will be interpret as the weight a bettor on $f$ attaches to this frequency. Pairs (frequency favourite losses, $\pi_{l}^{f}$ ) are represented by circles on Figure 1. 
Figure 1

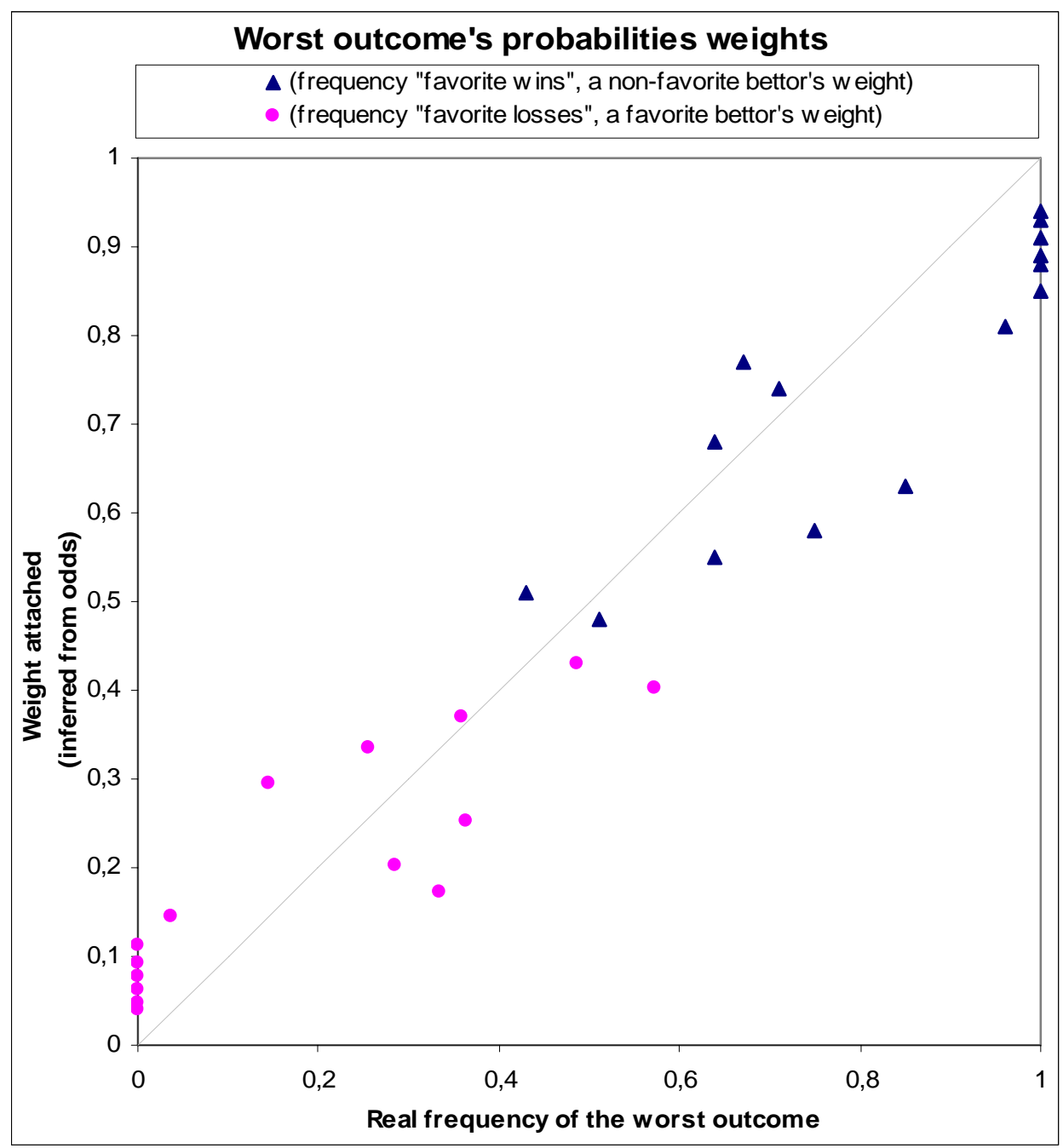

We interpret this Figure 1 as a representation of the frequencies that an event occurs and of the weights that different bettors give to those frequencies.

High frequencies of the favourite to win are associated with weights that are lower than those frequencies, i.e., the market's odds underestimate the real favorite's chances to win the match, and low frequencies of the favourite to lose are associated with weights that are higher than those frequencies, an evidence of the well-known long-shot bias.

We have estimated two functions that fit the points on this graph. An OLS regression between "real p" the frequency that at each odds the worse event occurs and the weight that bettors give to the worse event $-\pi-$. And a nonlinear probability weighting function between those two variables. The OLS linear function we have obtained is

$$
\pi=.104+.72 \text { "real p" with an adjusted } R^{2}=.865
$$

shown in Figure 2. Where the constant is significativelly greater than zero with a $95 \%$ degree of confidence and the slope is lower than 1 with the same degree of confidence. We conclude that evidence of the long-shot bias is found. 
Figure 2

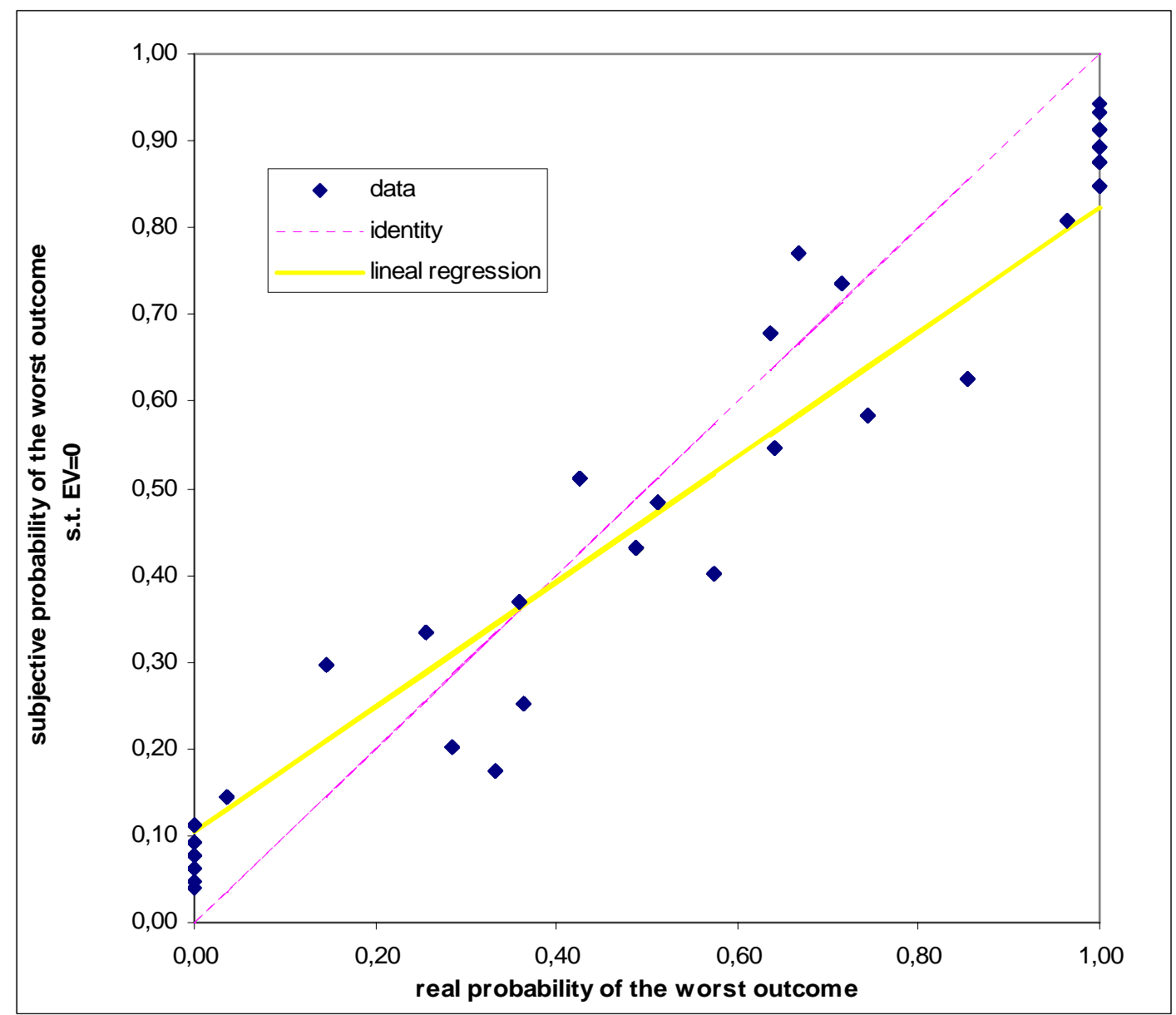

We have estimated the following function

$$
\pi=\frac{\delta(\text { "real p") }}{\delta(\text { "real p") })^{\gamma}+(1-" \text { real p" })^{\gamma}} \quad R^{2}=.839
$$

with $\delta=.84$ and $\gamma=.55$ both significativelly lower than 1 at the $95 \%$ degree of confidence, Figure 3. For this parameter values $\pi($ "real p" $)+\pi(1-"$ real p") $<1$ for all "real p". Therefore we have obtained a weighting function of optimistic bettors that overestimate low probabilities and underestimate high ones. In addition $\mathrm{p}^{*}$ (cross point with the identity line) is 0.38 , very close to that obtained in Gonzalez, R. and G. Wu (1999). 
Figure 3

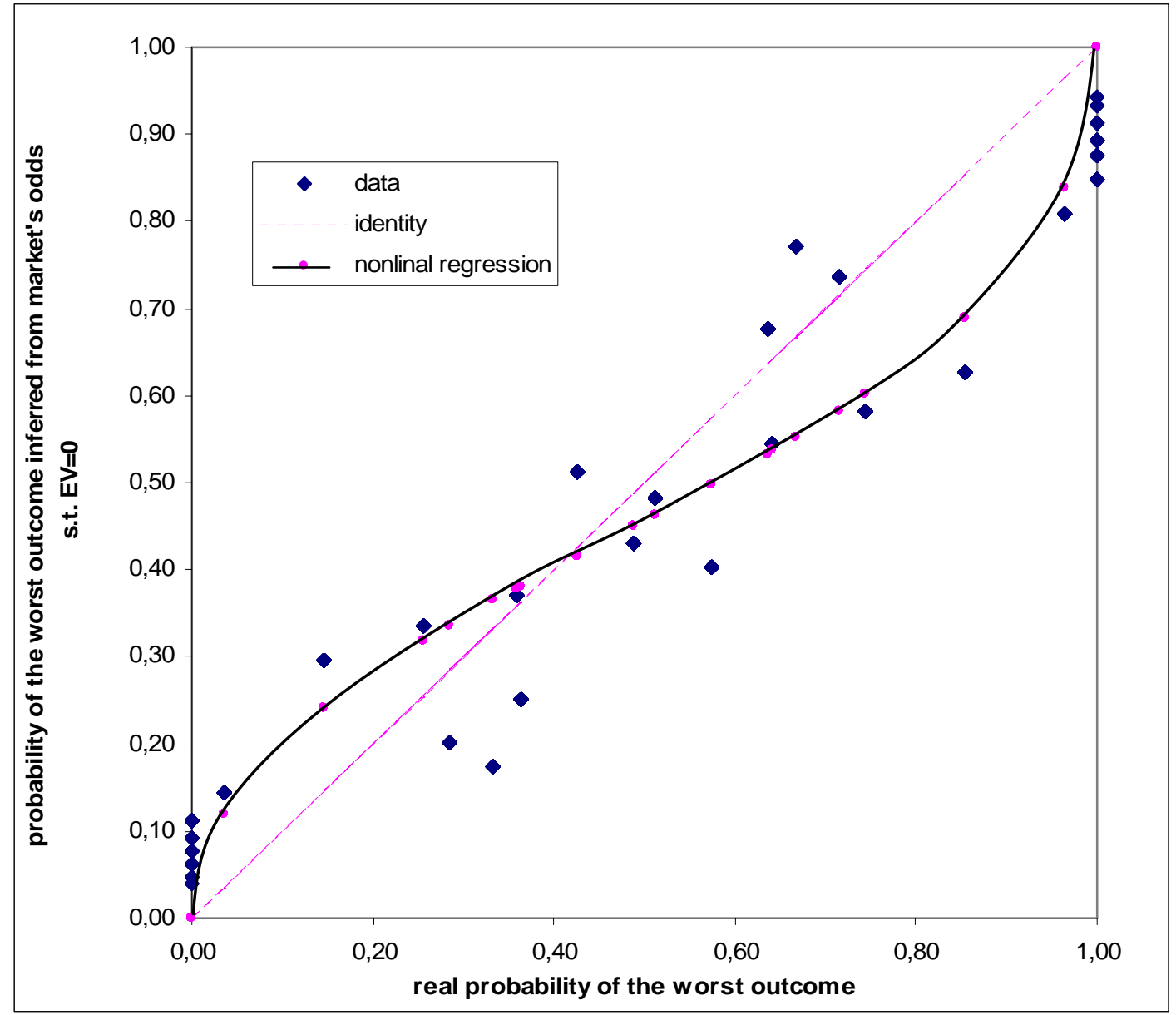

Our findings are similar to that obtained in other studies. 


\section{Summary and concluding remarks}

Although the Pelota betting system has operated for centuries in País Vasco, Navarra and La Rioja there are no written rules that govern the system. Here we have written such rules and explained the market institution. This betting market uses the odds system but in a way that differs from the pari-mutuel betting system and from bookmaking. In Pelota games a bettor bets against another bettor through a middleman who gets a 16 percent commission of the money won in each bet. Bets can be placed during the whole match and the odds change as points are scored. When a bet is made the odds arranged are fixed and determine the money won or lost at the end of the mach when the uncertainty about who is the winner is solved.

The classical decision theory of expected utility maximization can not explain this market assuming bettors are identical, thus we explain the existence of bets in the market under Quiggin's rank dependent expected utility model. We find that bettors have to be optimistic in order to explain the existence of a bet.

A first analysis to field data is made. Although few data are studied, the analysis is based on observed bets actually made, and we find that in the market there is evidence of underestimation of the favourite's chances to win, supporting the well-known long-shot bias. 


\section{References}

Blinder, Alan S.,Elie R.D. Canetti,David E.Lebow, and Jeremy B. Rudd, Asking About Prices. A New Approach to Understanding Price Sickiness, Rusell Sage Foundation, New York,1998.

Gonzalez, R. and G. Wu (1999): On the Shape of the Probability Weighting Function. Cognitive Psychology 38, $129-166$.

Kahneman, D. and Tversky, A. (1979): "Prospect theory: an analysis of decision under risk," Econometrica 47 (2), 263-91.

Köbberling, V., Schwieren, C., and Wakker, P. P. (2004) "Prospect-Theory's Diminishing Sensitivity Versus Economic's Intrinsic Utility of Money: How the Introduction of the Euro Can Be Used to Disentangle the Two Empirically,” Working Paper, December 2004.

Lattimore, P.K., J. K. Baker, and A. D. Witte. (1992): "The influence of probability on risky choice: A parametric examination," Journal of Economic Behavior and Organization 17, 377-400.

Quiggin, J. (1982): “A theory of anticipated utility," Journal of Economic Behavior and Organisation, 3, 323--43.

Quiggin, J. (1993): Generalized Expected Utility Theory: the Rank-Dependent Model. Kluwer Academic Publishers.

Sauer, R.D. (1998): “The Economics of Wagering Market," Journal of Economic Literature, XXXVI, 2021-2064.

Tversky, A. and D. Kahneman (1992): Advances in Prospect Theory: Cumulative Representation of Uncertainty, Journal of Risk and Uncertainty, 5, 297-323.

Woodland, L. M., and B. M. Woodland (1994): "Market Efficiency and the Favorite Long Shot Bias: The Baseball Betting Market," Journal of Finance, 49:1, 269-80 


\section{Appendix}

\section{Appendix: RDEU Maximizers' Indifference Curves}

We emphasize that RDEU maximizers' IC equation is different when betting on reds than when betting on blues. As its name says the RDEU functional depends on the prospects outcome "ordered" from worst to best. Thus a RDEU maximizer's utility depends on bettor's behavior. When betting on blues the worst outcome is $r$ thus the weighting function is applied directly to the probability of this worst outcome, i.e., $q\left(p_{r}\right)$, and the weight attached to the probability of $b$ is the complementary one (remember probability weights adds to one). Similarly when betting on reds the worst outcome is $b$ thus the weighting function is applied directly to $b$ 's probability, i.e., $q\left(1-p_{r}\right)$. We differentiate the utility when the worst outcome occurs if $b$ from the case when the worst is $r$.

In order to represent an IC we do it in the graph which axes are $\mathrm{X}$, consumption when $r$, and $\mathrm{Y}$, consumption when $b$. Thus

When $X>Y$ the worse outcome is $b$, as occurs when betting on the reds, and the rank dependent utility for the prospect is

$$
\operatorname{RDEU}\left(\left\{(Y, X) ;\left(1-p_{r}, p_{r}\right)\right\}\right)=q\left(1-p_{r}\right) U(Y)+\left(1-q\left(1-p_{r}\right)\right) U(X) .
$$

When $X<Y$, as happens when betting on the blues,

$$
\operatorname{RDEU}\left(\left\{(X, Y) ;\left(p_{r}, 1-p_{r}\right)\right\}\right)=q\left(p_{r}\right) U(X)+\left(1-q\left(p_{r}\right)\right) U(Y) .
$$

Thus, the IC's equation depends on which is bigger, $\mathrm{X}$ or $\mathrm{Y}$.

When $X>Y$, the IC's equation for a fixed utility of $\overline{\mathrm{U}}$ is

$$
\bar{U}=q\left(1-p_{r}\right) U(Y)+\left(1-q\left(1-p_{r}\right)\right) U(X)
$$

Moving $\mathrm{X}$ and $\mathrm{Y}$ inside the IC:

$$
\begin{gathered}
0=\frac{\delta \mathrm{RDEU}}{\delta \mathrm{X}} \mathrm{dX}+\frac{\delta \mathrm{RDEU}}{\delta \mathrm{Y}} \mathrm{dY} \\
0=\left(1-q\left(1-p_{r}\right)\right) U^{\prime}(X) \mathrm{dx}+q\left(1-p_{r}\right) U^{\prime}(Y) \mathrm{dy} \\
-\frac{\mathrm{dY}}{\mathrm{dX}}=\frac{\left(1-q\left(1-p_{r}\right)\right)}{q\left(1-p_{\mathrm{r}}\right)} \frac{U^{\prime}(X)}{U^{\prime}(Y)}
\end{gathered}
$$

If $X<Y, X$ is the worst outcome, thus the IC's equation is 


$$
\bar{U}=q\left(p_{r}\right) U(X)+\left(1-q\left(p_{r}\right)\right) U(Y) .
$$

Moving within the IC

$$
\begin{gathered}
0=\frac{\delta \mathrm{RDEU}}{\delta \mathrm{X}} \mathrm{dX}+\frac{\delta \mathrm{RDEU}}{\delta \mathrm{Y}} \mathrm{dY} \\
0=q\left(p_{r}\right) U^{\prime}(X) \mathrm{dx}+\left(1-q\left(p_{r}\right)\right) U^{\prime}(Y) \mathrm{dy} \\
-\frac{\mathrm{d} \mathrm{Y}}{\mathrm{dX}}=\frac{q\left(p_{r}\right)}{\left(1-q\left(p_{r}\right)\right)} \frac{U^{\prime}(X)}{U^{\prime}(Y)}
\end{gathered}
$$

Notice that $-\mathrm{dY} / \mathrm{dX} \quad$ is the marginal relation of substitution between $\mathrm{Y}$ and $\mathrm{X}$ $\left(\mathrm{RMS}_{\mathrm{X}, \mathrm{Y}}\right)$. It is the slope of the indifference curve. We emphatize the following:

1. When $\mathrm{X}>\mathrm{Y}$, as it occurs when betting on the reds, then the IC's slope is $-\frac{\mathrm{dY}}{\mathrm{dX}}=\frac{\left(1-q\left(1-p_{\mathrm{r}}\right)\right)}{q\left(1-p_{\mathrm{r}}\right)} \frac{U^{\prime}(X)}{U^{\prime}(Y)}$

2. When $\mathrm{X}<\mathrm{Y}$, as it occurs when betting on the blues, then the IC's slope is $-\frac{\mathrm{dY}}{\mathrm{dX}}=\frac{q\left(p_{r}\right)}{\left(1-q\left(p_{r}\right)\right)} \frac{U^{\prime}(X)}{U^{\prime}(Y)}$.

3. If individuals are optimistic, see Quiggin, J. (1982), $1>q\left(p_{r}\right)+q\left(1-p_{r}\right)$ then $\frac{\left(1-q\left(1-p_{r}\right)\right)}{q\left(1-p_{r}\right)}>\frac{q\left(p_{r}\right)}{\left(1-q\left(p_{r}\right)\right)}$ is bigger than when betting $\epsilon \longrightarrow 0$ on blues.

4. If individuals are not optimistic, see Quiggin, J. (1982), $1-q\left(1-p_{r}\right)<q\left(p_{r}\right)$ then $\frac{1-q\left(1-p_{r}\right)}{q\left(1-p_{r}\right)}<\frac{q\left(p_{r}\right)}{1-q\left(p_{r}\right)}$ bigger than when betting $\epsilon \longrightarrow 0$ on blues.

5. If individuals' utility function is linear, $U^{\prime}(x)$ is constant, then IC are right with slope
a. $\frac{1-q\left(1-p_{r}\right)}{q\left(1-p_{r}\right)}$ if $\mathrm{X}>\mathrm{Y}$.
b. $\frac{q\left(p_{r}\right)}{1-q\left(p_{r}\right)}$ if $\mathrm{X}<\mathrm{Y}$,

6. If individuals' utility function are concave, $U$ ' ' $(x)$ lower than zero, then moving within a given IC, when increasing $\mathrm{X}$ (and decreasing $\mathrm{Y}$ ), $U^{\prime}(\mathrm{X})$ decreases, so that the IC's slope is lower. It follows that the IC are composed of two convex parts.

7. If individuals' utility function are convex, $U$ ' ' $(x)$ lower than zero, then moving within a given IC, when increasing $\mathrm{X}$ (and decreasing $\mathrm{Y}$ ), $U^{\prime}(\mathrm{X})$ increases, so that the IC's slope is higher. It follows that the IC are composed of two concave parts.

Let's see all the above cases graphically in the following page. 
Graphs: Different IC shapes of RDEU maximizers depending on the utility function on wealth and on the optimism.

Optimistic RDEU with linear $U(x)$

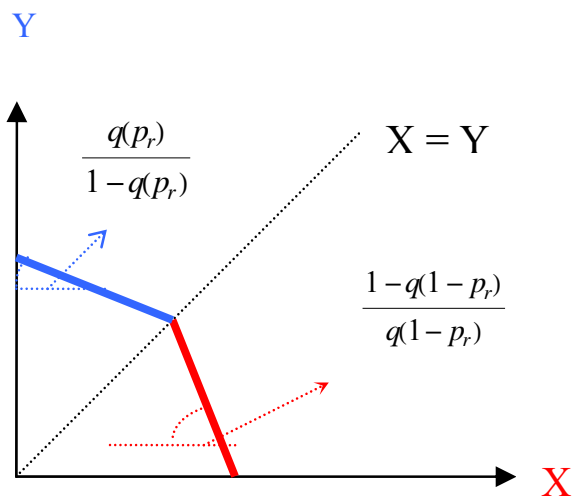

Optimistic RDEU with concave $U(x)$

Y

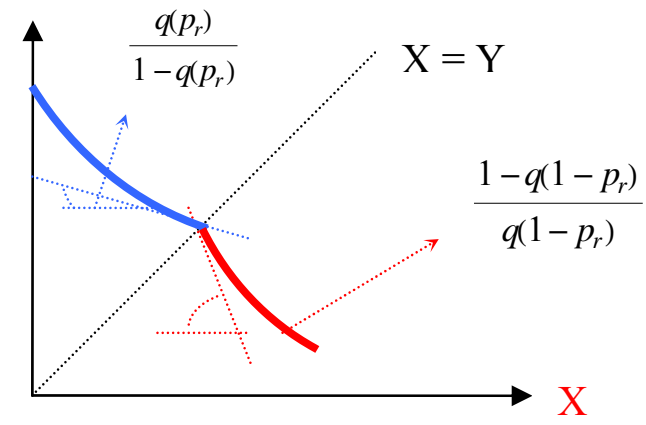

Optimistic RDEU with convex $U(x)$

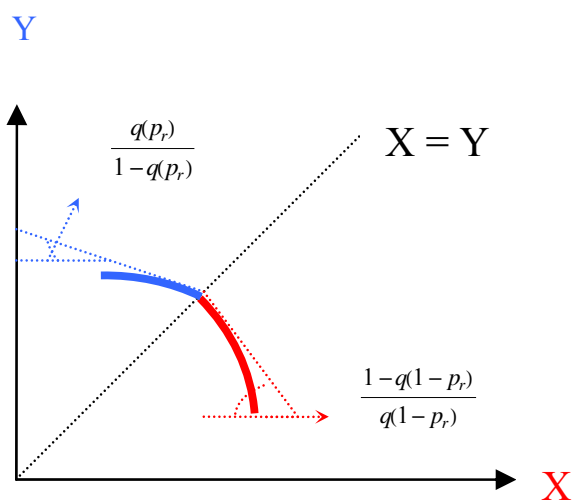

Pesimistic RDEU with linear $U(x)$

Y

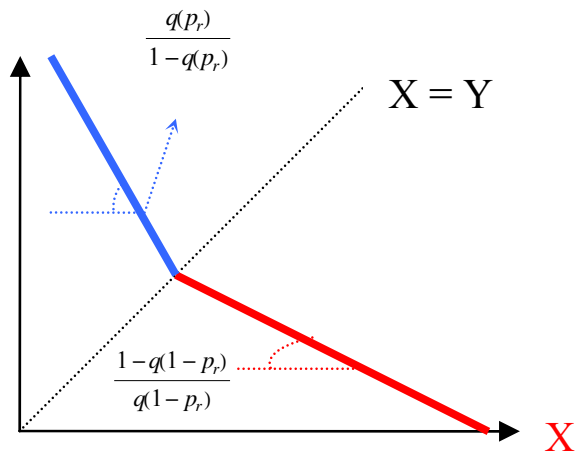

$\mathrm{Y} \quad \frac{q\left(p_{r}\right)}{1-q\left(p_{r}\right)}$

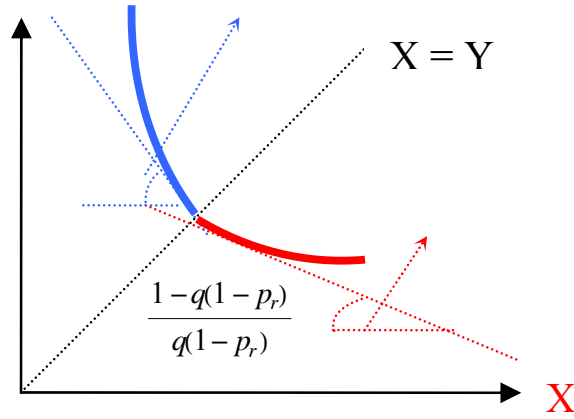

Pessimistic RDEU with convex $U(x)$

$\mathrm{Y}$

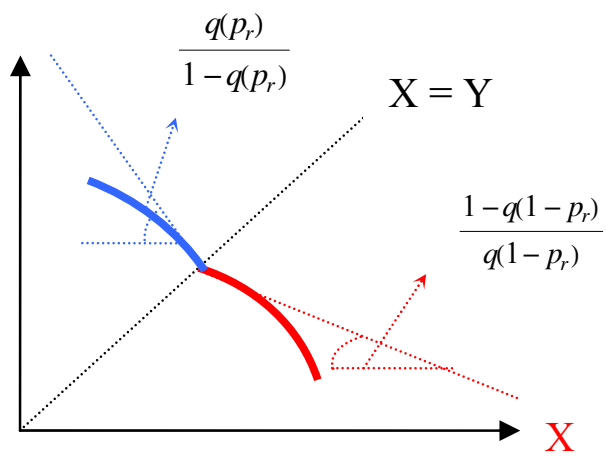

